\title{
The Effect of Transformational Leadership Style Practice on Academic Staff Commitment of Private Colleges Hawassa City
}

\author{
Abebayehu Mesele Sintayehu ${ }^{1} \quad$ Kanbiro Orkaido Deyganto ${ }^{2}$ \\ 1.Lecturer \& Academic Vice Dean, Pharma College Hawassa Campus, Hawassa, Ethiopia \\ 2.Lecturer \& Researcher, School of Graduate Studies, Pharma College Hawassa Campus, Hawassa, Ethiopia
}

\begin{abstract}
This study aimed to identify the effect of transformational leadership style practice on academic staff commitment of private colleges in Hawassa city. The researchers employed a quantitative research approach with an explanatory research design. A simple random sampling technique was employed to select academic staff from colleges. The result of regression analysis was applied to investigate the effect of transformational leadership style practice on academic staff commitment. The findings of this study showed that, challenge the process, inspiring a shared vision, enabling others to act, modeling the way, and encouraging the heart have positive and statistically significant effects on academic staff commitment. Hence, the paper suggested that private colleges should improve the transformational leadership style practices to encourage academic staff commitment.
\end{abstract}

Keywords: Transformational Leadership Style, Academic Staff, Commitment; Private Colleges

DOI: $10.7176 / \mathrm{JEP} / 12-25-02$

Publication date:September $30^{\text {th }} 2021$

\section{Introduction}

Increased access to education can contribute to reducing poverty. Education plays a great role in poverty alleviation and economic development. It increases the rate of return on the economy (Omoniyi, 2013). To achieve the goal for which the private colleges established, the most valuable and indispensable resource that private colleges needs are academic staff. Highly motivated employees of colleges can prove their utility. There are various tools and methods by which employees' motivational levels are often enhanced. One of these tools is the transformational style parctice style by leadars in educational institutions (Amin et al. 2018).

Transformational leaders continue to struggle with creating a positive school culture for academic staff and students, which will support and enable change, and that will develop their organization into a high-performing school. Transformational leaders can influence staff commitment so that such behavior has a positive impact on the organizations' outcome and performance (Gathungu et al., 2015). It fosters a climate of trust, nurtures employees 'confidence, and encourages their individual development. Transformational leaders also empower employees to participate in the decision-making process, thereby resulting in higher organizational commitment.

By allowing them to participate in deciding, it results in more empowered and motivated employees. Education institutions should maintain employees' positive attitudes and behavior by applying the transformational leadership style and ensuring job satisfaction through commitment (Giovanita \& Mangundjaya, 2017). This is why the effect of transformational leadership practices on staff commitment has become a burning issue in private colleges. Different researchers have addressed the issue and reached different conclusions. For instance, Amin et al. (2018), Kedir \& Geleta (2017), Giovanita \& Mangundjaya (2017), Gathungu et al. (2015), Biza \& Irbo (2020), Khan (2020), Saleem (2015), Şirin et al. (2018), Ahmad et al. (2018); Malcalm, \& Tamatey (2017), Temesgen (2017), Mengistu (2020), and Gearahayalsew (2019), and found out that transformational leadership has a positive effect on staff commitment.

The prior researches were on only focused on four dimensions of transformational leadership such as individualized consideration, intellectual stimulation, inspirational motivation, and idealized influence concerning other geographical locations which were over-researched. But the aforementioned studies did not address the issue in private colleges in Hawassa city. The research regarding the effect of transformational leadership practices on staff commitment in private colleges is overlooked. Since the current status of transformational leadership practice in the colleges has not been investigated and identified, there is insufficient data to inform policymakers in the design of mechanisms to enhance the quality of the private colleges.

This is the reason that motivated the researcher to research the effect of transformational leadership practices on academic staff commitment in private colleges in Hawassa city. The research was different from prior studies by using five models of transformational leadership developed by Kouzes and Posner (2002 include challenging the process, inspiring a shared vision, enabling others to act, modeling the way, and encouraging the heart that considered as explanatory variables and staff commitment was considered as the dependent variable of the study. The study was focused on examining the effect of transformational leadership practices on staff commitment of private colleges in Hawassa city by filling the aforementioned research gaps. The rest of the paper was organized as follows: Section 2 reviews related literature. Section 4 describes the methodology. Data analysis and discussion are included in section 5. Section 6 provides concludes the paper. Section 7 recommends a possible solution, 
Section 8 provides direction for future research. Section 8 deals with acknowledgment and section 9 are references the paper.

\section{Related literature}

Over the past few decades, debates over the most suitable role for leaders of educational institutions have been dominated by transformational leadership models (Hallinger, 2003). But most studies conducted in educational institutions did not consider the five practices model of transformational leadership. This study was considered five practices such as challenging the process, inspiring a shared vision, enabling others to act, modeling the way, and encouraging the heart (Kouzes and Posner, 2002). The operationalization and empirical review of these five leadership practices are presented as follows:

a) Challenging the process: Challenging the process suggests that leaders seek out things that appear to work and then insist that they are improved. Kouzes and Posner (2002) describe the challenge to the method practice as being the look for opportunities to vary the established order. Leaders search for innovative ways to enhance the organization. In doing so, they experiment and take risks. For transformational leaders, challenging the method may be a way of life. The empirical evidence by prior researchers like Amin et al. (2018), Kedir \& Geleta (2017), Giovanita \& Mangundjaya (2017), Gathungu et al. (2015), Biza \& Irbo (2020), Khan (2020), Saleem (2015), and Şirin et al. (2018) suggests that challenging the process version of transformational leadership practice has a positive effect on academic staff commitment.

H1: The challenging process of transformational leadership practice has a positive effect on affective academic commitment

b) Inspiring a shared vision: Inspiring a shared vision is significant for bringing people in any organization together to foster a commitment to a shared future they seek to make. Inspiring a vision involves watching the longer term with a passion to form a different and persuade others to have this vision. Inspiring a shared vision is a crucial aspect of leadership because leaders are expected to make and communicate organizational direction (Snee and Hoerl, 2004). Leaders breathe life into their visions and obtain people to ascertain exciting possibilities for the longer term (Kouzes and Posner, 2002). Transformational leaders passionately believe that they will make a difference by envisioning the longer term and creating a perfect and unique image of what the organization can become. They inspire such a vision in their followers with a positive and hopeful outlook. They generate enthusiasm and excitement for the common vision from others through genuineness and skillful use of metaphors, symbols, positive language, and private energy (Kouzes and Posner, 1995, 2002). The empirical studies by Amin et al. (2018), Kedir \& Geleta (2017), Giovanita \& Mangundjaya (2017), Gathungu et al. (2015), Biza \& Irbo (2020), Khan (2020), Saleem (2015), Sirin et al. (2018), Ahmad et al. (2018); Malcalm, \& Tamatey (2017), Temesgen (2017), Mengistu (2020), and Gearahayalsew (2019) found out that inspiring a shared vision of transformational leadership practice has a positive effect on affective staff commitment. So it can be hypotheses that:

H2: Inspiring a shared vision of transformational leadership practice has a positive effect on academic staff commitment

c) Enabling Others to Act: Enabling others to act is fostering collaboration and empowerment. It refers to leaders involving others in planning and giving them freedom of choice within the decision-making process. Enabling others to act allows followers to try to do their job and to understand their full potential. Transformational leaders strive to make an environment of trust and human dignity and to assist everyone feels capable and powerful. They consider the requirements and interests of others and allow them to feel as if they carry ownership and responsibility within the organization. Kouzes and Posner (2002) describe the "enable others to act" practice as a means of fostering collaboration and building spirited teams. Leaders actively involve others. The prior research findings by researchers such as Amin et al. (2018), Kedir \& Geleta (2017), Giovanita \& Mangundjaya (2017), Gathungu et al. (2015), Biza \& Irbo (2020), Khan (2020), Saleem (2015), Şirin et al. (2018), Ahmad et al. (2018); Malcalm, \& Tamatey (2017) found out that enabling others to act vision of transformational leadership practice has a positive effect on affective staff commitment in colleges. So that it is often hypothesized that:

H3: The enabling others to act vision of transformational leadership practice has a positive effect on affective academic staff commitment in colleges.

d) Modeling the Way: Modeling means being prepared to go first, living the behaviors they want others to adopt before asking them to adopt them. Leaders also unravel bureaucracy when it impedes action; they put up signposts when people are unsure of where to travel or the way to get there; and that they create opportunities for victory (Kouzes and Posner, 2002). The prior research findings by researchers such as Amin et al. (2018), Kedir \& Geleta (2017), Giovanita \& Mangundjaya (2017), Gathungu et al. (2015), Biza \& Irbo (2020), Khan (2020), Saleem (2015), Şirin et al. (2018), Ahmad et al. (2018); Malcalm, \& Tamatey (2017) found out that modeling the way vision of transformational leadership practice has a positive effect on affective staff commitment. So that it is often hypothesized that

H4: Modeling the way vision of transformational leadership practice has a positive effect on academic staff commitment. 
e) Encouraging the Heart: People often need encouragement and motivation to achieve the goals set by the organization. Successful leaders have high expectations for themselves and their employees. Their credibility is predicated on their record of achievements, dedication, and daily demonstrations of what and the way things got to be done. By influencing employee motivation, leaders attach rewards and recognition to job performance. To stay hope and determination alive, leaders recognize the contributions that individuals make. In every winning team, the members got to share the rewards of their efforts, so leaders celebrate accomplishments. Leaders make people feel like heroes (Kouzes and Posner, 2002). The prior research findings by academics such as Amin et al. (2018), Kedir \& Geleta (2017), Giovanita \& Mangundjaya (2017), Gathungu et al. (2015), Biza \& Irbo (2020), Khan (2020), Saleem (2015), Şirin et al. (2018), Ahmad et al. (2018); Malcalm, \& Tamatey (2017) found out that encouraging the heart vision of transformational leadership practice has a positive effect on affective staff commitment. So that it is often hypothesized that:

H5: Encouraging the heart vision of transformational leadership practice has a positive effect on academic staff commitment

\section{Conceptual framework of the study}

Conceptually, the study delaminated to identify the effect of five explanatory variables such as challenging the process, inspiring a shared vision, enabling others to act, modeling the way, and encouraging the heart on one dependent variable which was academic staff commitment.

Figure 1: Conceptual Frameworks

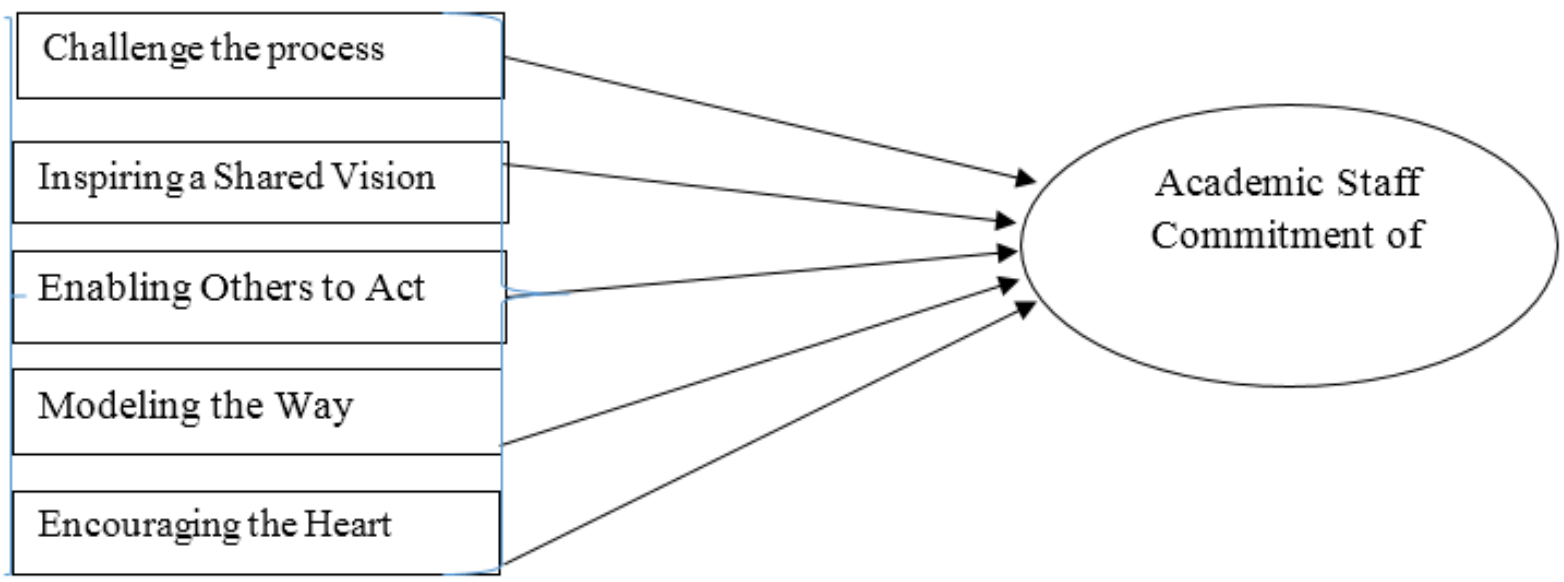

Source: Researchers' development (2021)

\section{Methodology of the Study}

4.1 Research design and Approach: The researchers have been used a quantitative research approach with explanatory study design to the objective of the study since the main objective of this study was to investigate the cause and effect relationships between staff commitment and transformational leadership practice.

4.2 Data type and Tools of data collection: In this study, the primary data sources were used for the objective of the study. It has collected through a structured questionnaire from respondents selected from private colleges in Hawassa city.

Target Population, Sample Size, and Selection Techniques: Target population refers to the population to which the study findings are generalized. The study was conducted on 120 from private colleges such as Pharma College, Furra College, Infolink colleges, Africa Beza College, Rift Valley University, New Global vison, Grand college, Unique star, Atlas College, Union College, Paradise College, US college, Shallom college, Radical International College, and Zion college in Hawassa city. To determine the sample size for this study, the researcher was used the mathematical formula of Yamane (1967) by taking into account the total population, the sampling error, and the level of reliability and it is assumed that the sample would have $95 \%$ reliability about population and a sampling error will be $5 \%$. This simplest formula is: -

Where $\mathrm{n}=$ sample size

$$
n=\frac{N}{1+\left(0.05^{2}\right) * N}
$$

$\mathrm{N}=$ target population

$$
\frac{120}{1+\left(0.05^{2}\right) * 820}=92
$$

Therefore, the representative sample size of this study was 92 respondents selected from three private colleges in Hawassa city. 
Table 1: Measurement of Dependent and Independent Variables.

\begin{tabular}{|l|l|l|l|}
\hline Category & Variables & Measurement & Expected Sign \\
\hline Dependent variable & Staff Commitment (SC) & Five-point literate scale & \\
\hline \multirow{4}{*}{ Independent Variables } & Challenge the Process(CTP) & Five-point literate scale & + \\
\cline { 2 - 4 } & Inspiring a Shared Vision(ISV) & Five-point literate scale & + \\
\cline { 2 - 4 } & Enabling Others to Act (EOA) & Five-point literate scale & + \\
\cline { 2 - 4 } & Modeling The Way(MTW) & Five-point literate scale & + \\
\cline { 2 - 4 } & Encouraging the Heart(ETW) & Five-point literate scale & + \\
\hline
\end{tabular}

Source: Own work based on literature review (2021).

\subsection{Data Analysis tools}

To meet the objective of the study, the research was used both descriptive and inferential statistics that have been done through SPSS version 21.0 to get the reliable research findings

\subsection{Econometrics Model Specification}

When it comes to model specification, staff commitment will be measured through a Likert scale questionnaire. The multiple linear regression model will be employed by the researcher to measure staff commitment'. The dependent variable (Academic staff commitment (ASC)is a linear function of, challenge the process (CTP), inspiring a shared vision (ISV), enabling others to act (EOA), modeling the way (MTW), and encouraging the heart(ETW)), the independent variables by CTP, ISV, EOA, MTW, ETW, and the error- by u, the model is given by the following Equation as:

$\mathrm{ASC}=\beta 0+(\beta 1 * \mathrm{CTP})++(\beta 2 * \mathrm{ISV})+(\beta 3 * \mathrm{EOA})+(\beta 4 * \mathrm{MTW})+(\beta 5 * \mathrm{ETW})+\mathrm{U}(1)$

Whereas:

ASC $=$ Academic Staff Commitment

$\beta 0=$ Constant term

$\beta 1, \beta 2, \beta 3, \beta 4 \& \beta 5$ refer to coefficients

$\mathrm{CTP}=$ Challenge the Process

ISV $=$ Inspiring a Shared Vision

$\mathrm{EOA}=$ Enabling Others to Act

MTW=Modeling the Way

ETW=Encouraging the Heart

$\ddot{\mathrm{U}}=$ Error term

\subsection{Reliability Test}

To measure the consistency of the questionnaire particularly the Likert-type scale, reliability analysis is important in reflecting the general reliability of constructs that it's measuring. In the current research, the researcher employed Cronbach's Alpha $(\alpha)$ which is that the commonest measure of scale reliability and worth greater than 0.7 is extremely acceptable. This has been tested as follow:

Table 2: Reliability Test

\begin{tabular}{|l|l|}
\hline Cronbach's Alpha & N of Items \\
\hline 0.987 & 30 \\
\hline
\end{tabular}

Source: Personal survey result, 2021

This indicates that all the variables under consideration accounts above the scientifically accepted threshold, therefore the study is reliable under this circumstance. compared with the minimum value of alpha 0.70 advocated by Cronbach's (1951), then the responses generated for all of the variables 'used in this research were reliable enough for data analysis. This implies that the data incorporated in SPSS is reliable.

\subsection{Validity Test}

The validity of the questionnaire is decided through face, content, and construct validity. First, the questions were framed in such a manner that it was easily understood and exactly conveyed its sense and purpose to the respondents. Moreover, the draft questionnaire was given to academic staff to view it in the light of the research objectives, its relevance, the adequacy of the questionnaire items, and question coverage. The score of the itemto-total correlations is more than 0.50 , and Cronbach's alpha, if item deleted, is more than 0.70 and not similar to the total Cronbach's alpha coefficient. So that we can conclude that validity is satisfied.

\subsection{Ethical Considerations}

The following ethical considerations were given attention by the researchers and enumerators while conducting the research that includes voluntary participation, no harm were participants, anonymity, and confidentiality, not 
deceiving the subjects, and privacy of participants. Conserving the voluntary participation of respondents, no participants were forced to take part in the research and participants were free to withdraw from the research at any moment. With regarding harm to participants, the researcher ensured that there is no physical or psychological harm done to the participants as a result of the study. When it comes to anonymity and confidentiality, all information gathered during the study were be handled confidentially and permission from the participants was obtained for all information to be shared publicly. Not deceiving the subjects since participants were informed clearly about the aim, purpose, and procedures of the study and will not be deceived in any way. Finally, Privacy of participants the privacy of participants was respected.

\section{Results of the study}

This part is dealing with the analysis and discussion of data collected from 80 respondents from private colleges in Hawassa city. Out of 92 questionnaires distributed to academic staff, 80 questionnaires were properly collected. The response rate was $87 \%$ which implies more than $50 \%$ of respondents have participated in the process of data collection. Then, the analysis of the data was based on the questionnaires collected using SPSS version 23.0. The first section of the analysis concerns descriptive statistics person correlation matrix, regression analysis, hypotheses testing, and summary of results.

\subsection{Summary of Descriptive Statistics}

Table 3: Summary of Descriptive Statistics

\begin{tabular}{|l|l|l|l|}
\hline Variables & N & Mean & Std. D \\
\hline Academic Staff Commitment & 80 & 4.6700 & 1.20347 \\
\hline Challenge the Process & 80 & 3.6000 & 1.11635 \\
\hline Inspiring a Shared Vision & 80 & 3.8000 & 1.32620 \\
\hline Enabling Others to Act & 80 & 3.2804 & .96773 \\
\hline Modeling The Way & 80 & 4.8300 & 1.24453 \\
\hline Encouraging the Heart & 80 & 3.8700 & .96840 \\
\hline
\end{tabular}

Source: Personal survey result, 2021

Academic Staff Commitment was the dependent variable of this study. As indicated in the above table 3, the Staff Commitment shows that private colleges have an overall mean of the variable was 4.6700a maximum of 5 and a minimum of 1 Likert scale values. The standard deviation value is 1.0845 which indicates there was a variation of actual responses from the mean. Concerning other variables the Challenge the Process 3.6000 with (SD) 1.11916 Inspiring a Shared Vision of mean 3.8000, (SD) of 1.32954, Enabling Others to Act 4.9980 with SD 0.75765 , modeling the way 3.8300 with SD of 1.24766, Encouraging the Heart 3.8700 with 0.97084 with SD have the overall mean and standard deviation respectively. In summary, all variables incorporated in the model have a moderate contribution to the response variable academic staff commitment in private colleges in Hawassa city.

\subsection{Correlation Matrix}

Correlation analysis measures the relationship between two items. The matrix for this study was computed as follow:

Table 4: Pearson Correlation Matrix

\begin{tabular}{|c|c|c|c|c|c|c|c|}
\hline \multicolumn{8}{|c|}{ Correlations } \\
\hline \multicolumn{2}{|c|}{ Variables } & $\mathrm{ASC}$ & CTP & ISV & EOA & MTW & ETW \\
\hline $\mathrm{ASC}$ & Pearson Correlation & 1 & & & & & \\
\hline \multirow[t]{2}{*}{ CTP } & Pearson Correlation & $.370 * *$ & 1 & & & & \\
\hline & Sig. (2-tailed) & .000 & & & & & \\
\hline \multirow[t]{2}{*}{ ISV } & Pearson Correlation & $.153 *$ & $.285 * *$ & 1 & & & \\
\hline & Sig. (2-tailed) & .031 & .000 & & & & \\
\hline \multirow[t]{2}{*}{$\mathrm{EOA}$} & Pearson Correlation & $.257 * *$ & .132 & .060 & 1 & & \\
\hline & Sig. (2-tailed) & .000 & .063 & .398 & & & \\
\hline \multirow[t]{2}{*}{ MTW } & Pearson Correlation & $.352 * *$ & -.129 & $-.452 * *$ & .045 & 1 & \\
\hline & Sig. (2-tailed) & .000 & .069 & .000 & .529 & & \\
\hline \multirow[t]{2}{*}{ ETW } & Pearson Correlation & $.368 * *$ & $-.262 * *$ & -.021 & .017 & $.399 * *$ & 1 \\
\hline & Sig. (2-tailed) & .000 & .000 & .766 & .810 & .000 & \\
\hline
\end{tabular}

Source: Personal survey result, 2021

Table 4 shows the relationship between the dependent variable which is staff commitment and independent variables with a coefficient of correlation 1 indicates that each variable is perfectly correlated with each other. The 
result shows that all five independent variables such as Challenge the process(CTP), Inspiring a Shared Vision(ISV), Enabling Others to Act (EOA), Modeling The Way(MTW), Encouraging the Heart(ETW) have a positive relationship with staff commitment since the $p$-value is more than $1 \%$ level of significance since the $p$ value is less than 0.01 . This implies transformational leadership practice has a positive and significant relationship with staff commitment in private colleges in Hawassa city.

\subsection{Assessment of Ordinary Least Square Assumptions}

Ordinary Least Squares (OLS) is the most common estimation method for linear models and that's true for a good reason. As long as your model satisfies the OLS assumptions for linear regression, we can rest easy knowing that we're getting the best possible estimates. The most common assumptions to be tested before running the final regression result are normality, multicollinearity, autocorrelation, and heteroscedasticity. So the model used for this study was the best fit.

\subsection{The Regression Results (Inferential Statistics)}

Table 5: Regression Results

$\mathrm{R}=.680, \mathrm{R}^{2}=.462$, Ad $\mathrm{R}^{2} .448$,Std. Error of the Estimate $=.89408$, Durbin-Watson $(\mathrm{d})=1.888, \quad \mathrm{~F}$-statistic $=$ 33.310 P-value $=0.000$, ANOVA with ( $\mathrm{p}$-value of 0.000

\begin{tabular}{|c|c|c|c|c|c|c|c|c|c|c|c|}
\hline \multirow{2}{*}{\multicolumn{2}{|c|}{ Model }} & \multicolumn{2}{|c|}{$\begin{array}{l}\text { Unstandardized } \\
\text { Coefficients }\end{array}$} & $\begin{array}{l}\text { Standardized } \\
\text { Coefficients }\end{array}$ & \multirow[t]{2}{*}{$\mathrm{t}$} & \multirow[t]{2}{*}{ Sig. } & \multicolumn{3}{|c|}{$\begin{array}{l}95.0 \% \text { Confidence } \\
\text { Interval for B }\end{array}$} & \multicolumn{2}{|c|}{$\begin{array}{l}\text { Collinearity } \\
\text { Statistics }\end{array}$} \\
\hline & & $\mathrm{B}$ & $\begin{array}{l}\text { Std. } \\
\text { Error }\end{array}$ & Beta & & & $\begin{array}{l}\text { Lower } \\
\text { Bound }\end{array}$ & $\begin{array}{l}\text { Upper } \\
\text { Bound }\end{array}$ & Toler & ance & VIF \\
\hline \multirow[t]{6}{*}{1} & (Constant) & -2.859 & .378 & & -4.920 & .000 & -2.604 & -1.114 & & & \\
\hline & CTP & .438 & .062 & .406 & 7.008 & .000 & .315 & .561 & .825 & & 1.211 \\
\hline & ISV & .174 & .058 & .192 & 3.020 & .003 & .060 & .288 & .687 & & 1.456 \\
\hline & EOA & .212 & .066 & .170 & 3.190 & .002 & .081 & .342 & .975 & & 1.025 \\
\hline & MTW & .337 & .064 & .349 & 5.255 & .000 & .211 & .464 & .630 & & 1.588 \\
\hline & ETW & .419 & .076 & .337 & 5.495 & .000 & .268 & .569 & .738 & & 1.356 \\
\hline
\end{tabular}

a. Dependent Variable: staff commitment

Source: Personal survey, 2021

Equation of the result; Academic Staff commitment $=-2.859+0.438 * \mathrm{CTP}+0.194 * \mathrm{ISV}+0.212 * \mathrm{EOA}+0.337 *$ MTW + 0.419* ETW +Error... (2)

The regression result was presented in the above table $5 \mathrm{R}$-squared was measured the goodness of fit of the explanatory variables in explaining the variations in staff commitment (SC) the Adjusted-R-squared statistics of the model was 44.8 percent. The result indicates that 44.8 percent variation in the dependent variable was jointly explained by the explanatory variables in the model. Whereas, the remaining 55.2 percent of the variation in the staff commitment (SC) (as measured by the Likert scale) is explained by other variables which are not included in the model. The coefficient of explanatory variables such as challenge the process(CTP) 0.438 , challenge the process(CTP)0.194, inspiring a shared vision (ISV) 0.212, modeling the way (MTW) 0.337, encouraging the heart(ETW) 0.419 implies that $1 \%$ increase in the variables leads to $43.8 \%, 19.4 \%, 17.5 \%, 21.2 \%$, and $41.9 \%$ increase independent variable. Besides, the F-statistics (33.310) in the model summary and ANOVA with (pvalue of 0.000 ) which is used to test the overall significance of the model was presented and indicates the reliability and validity of the model at a 1 percent level of significance. This tells us that the model as a whole is statistically significant

\subsection{Discussion of Regression Result}

In addition, more explanation of the model of this research, let us discuss each variable incorporated in the model one by one as follow: The result of this study shows that support from challenge the Process (CTP) practice of transformational leadership with an unstandardized coefficient of regression $[\beta=0.438]$ has a positive and statistically significant at $1 \%$ level of significance since (p-value of $0.000<0.01$ ). Hence, hypothesis one is accepted. This finding is consistent with the idea of studies result by Amin et al. (2018), Kedir \& Geleta (2017), Giovanita \& Mangundjaya (2017), Gathungu et al. (2015), Biza \& Irbo (2020), Khan (2020), Saleem (2015), and Şirin et al. (2018) suggest that challenging the process version of transformational leadership practice has a positive effect on affective staff commitment educational institutions. This implies that challenge the process parameter of transformational practice is positively contributes to the academic staff commitment of private colleges in Hawassa city.

The result of this study with regards to Inspiring a Shared Vision(ISV) showed an unstandardized coefficient of regression $[\beta=0.194]$ has positive and statistically significant at $1 \%$ level of significance since ( $p$-value of $0.003<0.01)$. Hence, the researcher accepted hypothesis two. This finding is consistent with the finding of 
another study result of Biza \& Irbo (2020), Khan (2020), Saleem (2015), Şirin et al. (2018), Ahmad et al. (2018); Malcalm, \& Tamatey (2017), Temesgen (2017), Mengistu (2020), Amin et al. (2018), Kedir \& Geleta (2017), Giovanita \& Mangundjaya (2017), Gathungu et al. (2015), and Gearahayalsew (2019) found out that inspiring a shared vision of transformational leadership practice has a positive effect on staff commitment. This implies employee's commitment is positively influenced by inspiring a shared vision of transformational leadership practice.

Concerning enabling others to act (EOA), regression results showed $[\beta=0.337]$ is positive and statistically significant. Therefore, hypothesis three was is accepted by the researcher. This finding is inconsistent with the Amin et al. (2018), Kedir \& Geleta (2017), Giovanita \& Mangundjaya (2017), Gathungu et al. (2015), Biza \& Irbo (2020), Khan (2020), Saleem (2015), Şirin et al. (2018), Ahmad et al. (2018); Malcalm, \& Tamatey (2017) found out that enabling others to act vision of transformational leadership practice has a positive effect on staff commitment. This tells us Increased enabling others to act can lead to higher employees' commitment.

The result of this study also shows that the coefficient of regression modeling the way (MTW) is $[\beta=0.337]$ positive and statistically significant effect on employees commitment since (p-value of $0.00<0.05$ ). Hence, hypothesis four is accepted. This finding is similar to the findings of Amin et al. (2018), Kedir \& Geleta (2017), Giovanita \& Mangundjaya (2017), Gathungu et al. (2015), Biza \& Irbo (2020), Khan (2020), Saleem (2015), Şirin et al. (2018), Ahmad et al. (2018); Malcalm, \& Tamatey (2017) found out that modeling the way vision of transformational leadership practice has a positive effect on affective staff commitment showed that existence of modeling the way has positive and statistically effect on employees commitment. This implies that modeling the way helps employees see that their institution's success as an overall.

When comes to encouraging the heart the unstandardized coefficient of regression of variable is $[\beta=0.441]$ is positive and statistically significant with a p-value $(0.000>5 \%$ level of significance. Therefore, hypothesis five is accepted by the researcher. This finding is consistent with the empirical result of Giovanita \& Mangundjaya (2017), Gathungu et al. (2015), Biza \& Irbo (2020), Khan (2020), Saleem (2015), Şirin et al. (2018), Ahmad et al. (2018); Amin et al. (2018), Kedir \& Geleta (2017), Malcalm, \& Tamatey (2017) found out that encouraging the heart vision of transformational leadership practice has a positive effect on academic staff commitment of private colleges in Hawassa city. This implies that encouraging the heart vision can have a significant impact on morale and productivity that encourage commitment.

\section{Conclusions}

In this thesis work, the researcher explored the effect of five transformational leadership practices on academic staff commitment of private colleges in Hawassa city. By keeping this objective in mind, the researcher collected the primary data through a self-administrated questionnaire developed in the form of a five-point Likert scale from 80 respondents. By using SPSS version 23.0, the analysis of both descriptive and inferential statistics has been done. Based on the findings from the descriptive analysis, the researchers had concluded that academic staff commitment of private colleges in Hawassa city is generating positive employee commitment through five transformational leadership practices. Based on the findings from the regression analysis of the model, the researchers concluded that the staff commitment is best was best explained by the explanatory variables included in the model. Based on the regression analysis result, the researcher accepted hypotheses one up to five.

\section{Recommendations}

This study was evidenced that five transformational leadership style practices such as challenge the process, inspiring a shared vision, enabling others to act, modeling the way, and encouraging the heart to have a positive contribution towards employees' academic staff commitment of private colleges in Hawassa city. Based on findings, the researchers suggested that academic staff commitment of private colleges in Hawassa city should allow followers to express creativity. It is important to provide intellectual stimulation to the followers by being a role model, passion is important, effective communication and listening skills, develop a positive attitude of employees and encourage team members to contribute to organizational success.

\section{Directions for the Future Research}

Since any study can't be free from limitations, accordingly there are some limitations in the current study. In the beginning, it focused only on identifying the effect of five transformational practices on academic staff commitment of private colleges in Hawassa city. The Adjusted-R-squared statistics of the model were 44.8 percent. The result indicates that 44.8 percent variation in the dependent variable was jointly explained by the explanatory variables in the model. Whereas, the remaining 55.2 percent of the variation in the employee's motivation (as measured by the Likert scale) is explained by other variables which are not included in the model. The other researcher should incorporate more variables to enhance adjusted R2 with an equivalent topic at an equivalent study area. In another way, the findings of this study may be difficult to generalize about all $\mathrm{p}$ academic staff commitment of private colleges in Ethiopia, Africa, and the world in general. Hence, this study can be improved 
if it will be done at the regional, national, continental, and international levels by comparing different factors affecting transformational leadership practices and staff commitment.

\section{Acknowledgements}

Before all, we would like to extend our heartfelt thanks to God. Next to Good, we increase in value to Pharma College which is the topic private college in Hawassa city for initiating us to conduct this research. Great thanks go to Pharma College for motivating us to conduct this research paper.

\section{References}

Ahmad, F., Abbas, T., Latif, S., \& Rasheed, A. (2014). Impact of Transformational Leadership on Employee Motivation in Telecommunication Sector. Journal of Management Policies and Practices. 2(2), pp. 11-25

Amin, W., Akram, U., Shahzad, F., \& Amir, M. (2018). Impact of Transformation Leadership on Affective Employee's Commitment. European Online Journal of Natural and Social Sciences. 7(1). 48-57

Biza, T.A., \& Irbo, M.M. (2020). The impact of leadership styles on employee commitment in Madda Walabu University. African Journal of Business Management, 14 (9), 291-300. DOI: 10.5897/AJBM2018.8603

Gathungu, E., Iravo, D.M., \& Namusonge, P.G. (2015). Transformational Leadership and Employee's Commitment: Empirical Review. 20(7), 1-7: DOI: 10.9790/0837-20720107

Giovanita, D., \& Mangundjaya, W.L. (2017). The Effect of Transformational Leadership and alter Self-Efficacy on Employees' Commitment to vary. World Academy of Science, Engineering and Technology, International Journal of Psychological and Behavioral Sciences, 4.

Hallinger, P. (2003). Leading Educational Change: Reflections on the Practice of Instructional and Transformational Leadership. Cambridge Journal of Education, 33, 329352.http://dx.doi.org/10.1080/0305764032000122005

Kedir, K., \& Geleta, A. (2017). Leading educational change: The practices of transformational leadership within the Ethiopian technical vocational training and training (TVET) institutions. Vocational and Technical Education, 9(5), 49-61. DOI: 10.5897/IJVTE2017.0233

Khan, M.S. (2020). The Impact of Leadership Styles on Employees' Commitment in Higher Educational Context. Kouzes, J.M. and Posner, B.Z. (2002) The Leadership Challenge. 3rd Edition, Jossey-Bass, San Francisco.

Omoniyi, M. B. I. (2013). The role of education in poverty alleviation and economic development: A theoretical perspective and counseling implications. British Journal of Arts and Social Sciences, 15(2), 176-185.

Saleem. H. (2015). The impact of leadership styles on job satisfaction and mediating role of perceived organizational politics. Procedia - Social and Behavioral Sciences 172 (2015) 563 - 569

Malcalm, E., \& Tamatey, S. (2017). Examining leadership style on employee performance within the public sector of Ghana. International journal of scientific and research publications, 7(11). 343-361

Temesgen Shega. (2017). Leading lyceum Teachers for Organizational learning: A Comparative Case Study of state and personal schools in Addis Ababa, Ethiopia. A dissertation submitted to The Center for Comparative Education and Policy Studies. AAU.

Mengistu Amare. (2020). the School Principal Power Source, Leadership Style and Teacher Commitment in Government Secondary Schools of SNNPR: Nexus and Challenges focused. Dissertation. Submitted to AAU.

Gearahayalsew Paulos. (2019). Leadership Style and Employees' Commitment in Ethiopian Institute of Agricultural Research. A Thesis Submitted to the Department of Educational Planning and Management in Partial Fulfillment of the wants for Master of Arts Degree in Educational Leadership and Management. AAU.

Şirin, Y.E., Aydin, Ö.Z., \& Bilir, F.P. (2018). Transformational-Transactional Leadership and Organizational Cynicism Perception: education and Sports Teachers Sample. Universal Journal of Educational Research, 6 , 2008-2018.

Yamane, T. (1967). Elementary sampling theory. 